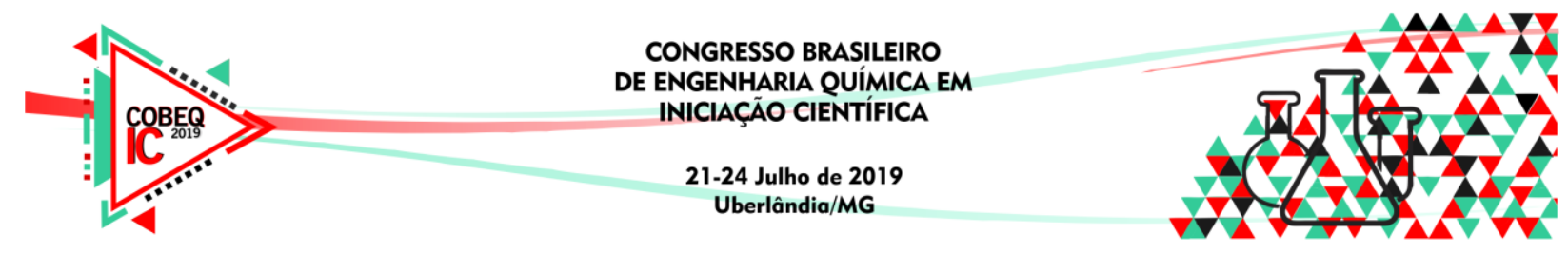

\title{
ESTUDO DA INFLUÊNCIA DA ADIÇÃO DE NUTRIENTES, SUCO DE MAÇÃ E LÚPULO NO PROCESSO DE PRODUÇÃO DO HIDROMEL
}

\author{
G. B. CALAIS ${ }^{1}$, A. M. L. MARTINS ${ }^{1}$, F. L. VASCONCELOS ${ }^{1}$, A. X. P. JUNIOR ${ }^{1}$ e T. L. S. \\ MIRANDA $^{1}$ \\ ${ }^{1}$ Universidade Federal de Minas Gerais, Departamento de Engenharia Química \\ E-mail para contato: guilhermecalais1@gmail.com
}

\begin{abstract}
RESUMO - A produção de mel é de grande relevância no cenário socioeconômico brasileiro. Como uma alternativa para agregar valor às sobras do processo de extração do mel, a produção de hidromel é uma atividade passível de ser realizada por produtores artesanais como forma de complementação de renda. O presente trabalho visa simular as condições de produção artesanal da bebida, avaliando a eficiência de produção de hidromel com e sem a adição de nutrientes de fermentação, bem como a adição de maçã e lúpulo. Ao todo, oito tipos de formulações foram preparados, variando entre a concentração de nutriente adicionado e o tipo de aditivo, em triplicata. Os mostos foram preparados em condições semelhantes às artesanais, com fermentação de aproximadamente 20 dias de duração, ao final do processo, todos os parâmetros fermentativos se enquadraram nos limites da legislação. Foram realizadas análises durante todo o processo fermentativo, tendo sido avaliados os parâmetros: $\mathrm{pH}$, variação de massa, etanol, metanol, açúcares redutores totais e acidez total, volátil e fixa. Os resultados para açúcar e etanol não apresentaram diferenças estatisticamente significantes para as amostras suplementadas e não suplementadas. A redução da massa apresentou estabilização em nível semelhante para os mesmos tipos de formulação investigados. Observou-se que a levedura utilizada é altamente adaptada ao mosto, eximindo o produtor artesanal da necessidade de suplementação, para esta levedura.
\end{abstract}

\section{INTRODUÇÃO}

O Brasil enquadra-se como um dos maiores produtores de mel, sendo o $8^{\circ}$ maior exportador mundial do produto. Contudo, na extração do mel acontecem perdas inerentes ao processo. Por ser um líquido altamente viscoso, parte do mel fica retido em utensílios e equipamentos do processo. Esse mel é lavado com água, apresentando hidratação superior a 20\%, o que inviabiliza sua comercialização como mel puro (Fernandes et al., 2006). Assim, a utilização de subprodutos da extração do mel é uma alternativa de modo a complementar a renda de pequenos produtores, agregando valor ao que seria um rejeito de processo (Mattietto et al., 2006).

O hidromel é uma bebida fermentada de mel e água e aparece, nesse cenário, como uma das alternativas de produtos derivados do mel. Na Europa, onde a bebida é mais popular, seu 


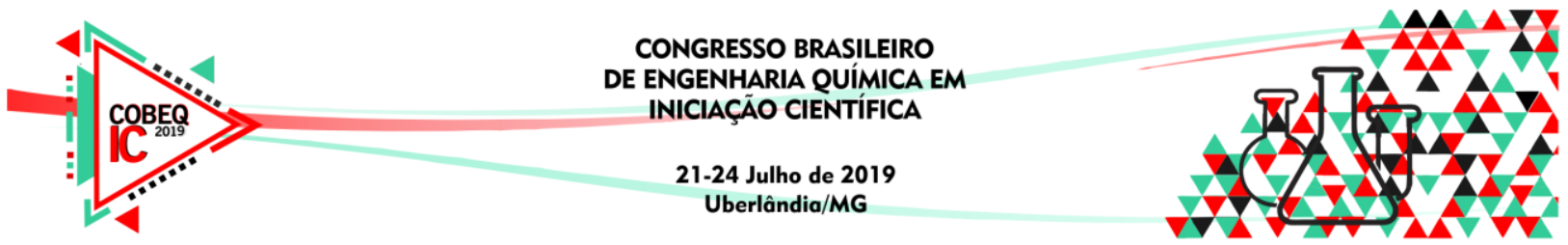

teor alcoólico varia entre $8 \%$ e $18 \%$ (Navrátil et al., 2001). Sua fermentação é considerada lenta, levando de 12 a 20 dias, e acontece por meio de inoculação de leveduras do tipo Saccharomyces.

Diante do exposto, o presente trabalho visa, sobretudo, popularizar a bebida que é tão pouco difundida no Brasil, apresentando-a como uma alternativa atrativa ao produtor artesanal de mel. Por essa razão, grande parte da metodologia foi realizada de modo a simular uma produção artesanal de hidromel, com insumos e equipamentos acessíveis ao pequeno produtor. Espera-se, assim, que o trabalho facilite o acesso e a eventual produção da bebida por parte de produtores artesanais. Para isso, o trabalho objetiva avaliar a necessidade de suplementação, bem como a viabilidade do uso de aditivos de maçã e lúpulo na sua produção.

\section{MATERIAIS E MÉTODOS}

Neste trabalho, as matérias-primas utilizadas foram: mel in natura - florada silvestre; água mineral (IGARAPÉ); levedura Saccharomyces cerevisiae M05 da marca Mangrove's Jack, Nutriente - extrato de levedura, suco de maçã integral sem conservantes, lúpulo desidratado e solução de iodo 12,5 ppm para sanitização de todos os equipamentos e materiais utilizados.

\subsection{Metodologia experimental}

As formulações foram preparadas com densidade inicial de, aproximadamente, 1,1 $\mathrm{g} / \mathrm{mL}$, com o objetivo de atingir teor alcoólico final de até $14 \%$, classificando o hidromel produzido como standard (Piatz, 2014). Quanto aos aditivos, utilizou-se suco de maçã integral sem conservantes e extrato de lúpulo, obtido a partir da fervura de $1,5 \mathrm{~g}$ de flor de lúpulo desidratada em $500 \mathrm{~mL}$ de água por $1 \mathrm{~h}$. O experimento, realizado em triplicata para cada formulação, foi preparado em 24 garrafas de $500 \mathrm{~mL}$ de água mineral e realizado por meio da adição de $300 \mathrm{~mL}$ de formulação em cada, conforme descrito na Tabela 1. Na Figura 1 mostra-se o sistema Airlock, adaptado nas garrafas para impedir a entrada de $\mathrm{O}_{2}$.

Tabela 1 - Composição do mosto para cada ensaio realizado

\begin{tabular}{|c|c|c|}
\hline Aditivos & Subtipos & Composição \\
\hline Branco & B & $250 \mathrm{~mL}$ de mosto e $50 \mathrm{~mL}$ de água \\
\hline \multirow{3}{*}{ Nutriente } & NB & $250 \mathrm{~mL}$ de mosto, $50 \mathrm{~mL}$ de água e $0,16 \mathrm{~g} / \mathrm{L}$ de nutriente \\
\hline & NI & $250 \mathrm{~mL}$ de mosto, $50 \mathrm{~mL}$ de água e $0,33 \mathrm{~g} / \mathrm{L}$ de nutriente \\
\hline & NA & $250 \mathrm{~mL}$ de mosto, $50 \mathrm{~mL}$ de água e $0,49 \mathrm{~g} / \mathrm{L}$ de nutriente \\
\hline \multirow[b]{2}{*}{ Lúpulo } & $\mathrm{L}$ & $250 \mathrm{~mL}$ de mosto, $50 \mathrm{~mL}$ de chá de lúpulo \\
\hline & LN & $\begin{array}{c}250 \mathrm{~mL} \text { de mosto, } 50 \mathrm{~mL} \text { de chá de lúpulo e } 0,33 \mathrm{~g} / \mathrm{L} \text { de } \\
\text { nutriente }\end{array}$ \\
\hline \multirow[b]{2}{*}{ Maçã } & $\mathrm{M}$ & $250 \mathrm{~mL}$ de mosto e $50 \mathrm{~mL}$ de suco integral de maçã \\
\hline & $\mathrm{MN}$ & $\begin{array}{c}250 \mathrm{~mL} \text { de mosto, } 50 \mathrm{~mL} \text { de suco integral de maçã e } 0,33 \\
\mathrm{~g} / \mathrm{L} \text { de nutriente }\end{array}$ \\
\hline
\end{tabular}




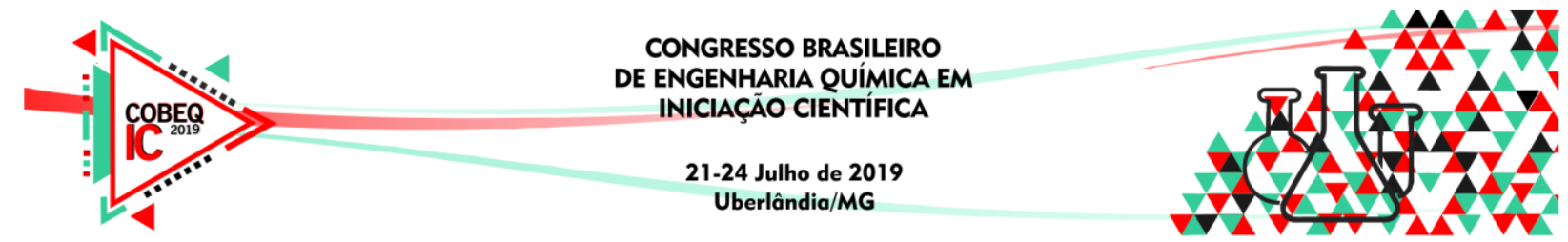

As siglas dos subtipos significam: B - Branco; NB, NI, NA - Nutriente em baixa, intermediária e alta concentração; L e LN - Lúpulo sem e com adição de nutriente; M e MN Maçã sem e com adição de nutriente.

Figura 1 - Garrafas plásticas contendo os mostos e com sistema airlock adaptado.

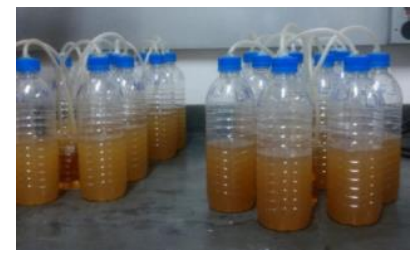

\subsection{Metodologia das análises}

Fez-se um pool das amostras de cada subtipo de modo a unir as triplicatas em um único recipiente. Todos os pools obtidos foram centrifugados por $10 \mathrm{~min}$ a $5000 \mathrm{rpm}$.

Análises físico-químicas: as análises de acidez total, acidez volátil, ART (Açúcares Redutores Totais), teor de etanol e teor de metanol foram realizadas de acordo com os métodos disponibilizados pelo Ministério da Agricultura, Pecuária e Abastecimento - MAPA (Brasil, 2017) e pela International Organisation of Vine and Wine - OIV (OIV, 2016).

Análise estatística: a comparação e validação estatística entre os diferentes tratamentos adotados neste trabalho foram realizadas por meio de teste de Tukey da diferença totalmente significativa (wholly significant difference - WSD).

\section{RESULTADOS E DISCUSSÃO}

No gráfico da Figura 2, é possível verificar a perda de massa total das formulações ao longo do processo fermentativo. A variação da massa do sistema é devida à conversão de açúcares em etanol e $\mathrm{CO}_{2}$, ocasionando a liberação de gás e diminuição da massa total.

Figura 2 - Perda de massa acumulada para todas as formulações testadas, ao longo do processo de fermentação.

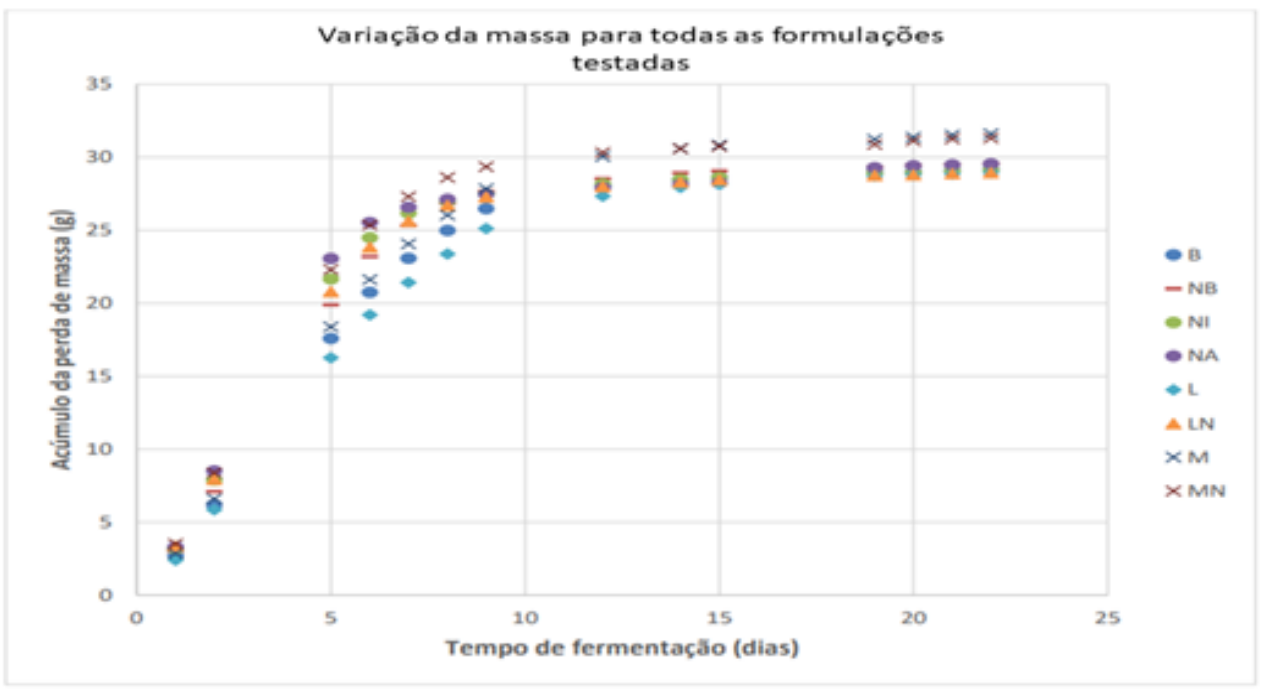




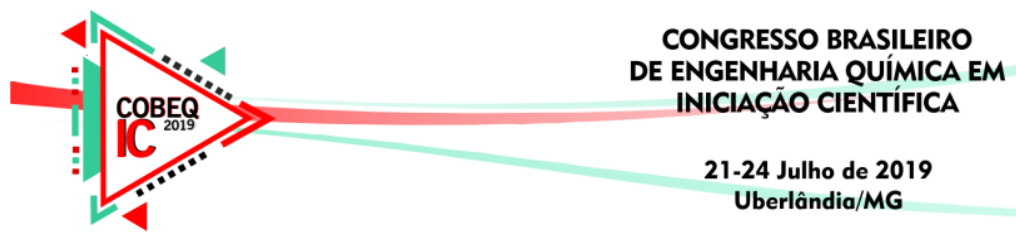

Por ser estritamente relacionada ao processo de fermentação, a variação de massa é largamente utilizada por produtores artesanais para acompanhar o desempenho fermentativo. A partir do dia 15 ocorre uma estabilização das curvas, indicando que para a maioria dos ensaios houve uma redução dos processos de conversão da glicose pelas leveduras devido, principalmente, à queda da disponibilidade de alimento e à intoxicação por etanol. Além disso, amostras que possuíam maior teor nutricional terminaram seu processo fermentativo antes, o que é comprovado pela estabilização de suas massas em um momento anterior quando comparado com as que sofreram menor suplementação.

Como o produto da conversão de açúcares em etanol é a liberação de gás carbônico, uma tendência de decaimento também pode ser observada quanto à concentração de açúcares totais nas formulações. Uma conversão em torno de $92 \%$ foi observada em todos os tratamentos, podendo-se inferir, portanto, que a levedura utilizada apresentou boa afinidade com os açúcares presentes nos mostos com diferentes tratamentos. Entretanto, essa conversão não pode ser relacionada diretamente à produção de álcool, uma vez que outros compostos são produzidos pelo processo metabólico das leveduras.

A Tabela 2 mostra que a concentração final média de açúcares é estatisticamente diferente apenas para a formulação nutriente intermediário (NI). Médias na mesma linha seguidas de letras iguais não diferem estatisticamente entre si a um nível de confiança de 95\%. Para as formulações com aditivos de maçã e lúpulo, a suplementação nutricional não foi estatisticamente significante para o consumo de açúcares (resultados não apresentados).

Tabela 2 - Resultados do teste de Tukey para as médias dos tratamentos com diferentes concentrações de nutriente

\begin{tabular}{|c|c|c|c|c|}
\hline \multirow{2}{*}{$\begin{array}{c}\text { Tempo de } \\
\text { Fermentação } \\
(\text { dias })\end{array}$} & Branco & NB & NI & NA \\
\cline { 2 - 5 } & & & & \\
\hline \hline 0 & $156,20 \pm 0,90^{\mathrm{a}}$ & $146,93 \pm 3,49^{\mathrm{ab}}$ & $151,82 \pm 1,73^{\mathrm{a}}$ & $143,72 \pm 0,83^{\mathrm{b}}$ \\
\hline 7 & $36,62 \pm 0,75^{\mathrm{a}}$ & $31,41 \pm 4,81^{\mathrm{ab}}$ & $25,63 \pm 0,64^{\mathrm{bc}}$ & $20,35 \pm 1,01^{\mathrm{c}}$ \\
\hline 14 & $12,45 \pm 0,66^{\mathrm{a}}$ & $15,83 \pm 0,48^{\mathrm{a}}$ & $13,06 \pm 1,79^{\mathrm{a}}$ & $14,19 \pm 2,13^{\mathrm{a}}$ \\
\hline 21 & $12,30 \pm 0,77^{\mathrm{a}}$ & $8,59 \pm 0,53^{\mathrm{b}}$ & $6,61 \pm 0,64^{\mathrm{c}}$ & $7,36 \pm 0,35^{\mathrm{bc}}$ \\
\hline 42 & $9,81 \pm 0,13^{\mathrm{b}}$ & $11,08 \pm 0,37^{\mathrm{b}}$ & $15,41 \pm 1,29^{\mathrm{a}}$ & $10,94 \pm 0,94^{\mathrm{b}}$ \\
\hline
\end{tabular}

Os resultados do teor de etanol para as diferentes formulações encontram-se na Tabela 3. Como se pode observar, a única diferença estatisticamente significante foi em relação à amostra de maçã suplementada, em relação à amostra que não recebeu complementação nutricional, provavelmente devido à maior quantidade total de nutrientes (suplemento + suco de maçã). Esses resultados reforçam e complementam a sugestão de que a levedura utilizada é fortemente adaptada ao mosto, não necessitando de nenhum tipo de suplementação. 


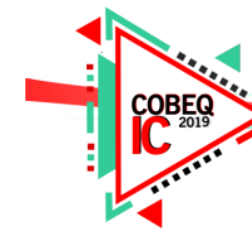

Tabela 3 - Teor Alcoólico das amostras de hidromel submetidas à suplementação nutricional e produzidas com adição de chá de lúpulo e suco de maçã

\begin{tabular}{|c|c|c|c|}
\hline Tratamento & $\left(\% \mathrm{v} / \mathrm{v}, 20^{\circ} \mathrm{C}\right)$ & Tratamento & $\left(\% \mathrm{v} / \mathrm{v}, 20^{\circ} \mathrm{C}\right)$ \\
\hline \hline B & $12,68 \pm 1,16^{\mathrm{a}}$ & $\mathrm{L}$ & $14,14 \pm 0,79^{\mathrm{c}}$ \\
\hline $\mathrm{NB}$ & $12,51 \pm 0,73^{\mathrm{a}}$ & $\mathrm{LN}$ & $15,23 \pm 1,67^{\mathrm{c}}$ \\
\hline NI & $13,74 \pm 1,53^{\mathrm{a}}$ & $\mathrm{M}$ & $14,02 \pm 1,58^{\mathrm{c}}$ \\
\hline NA & $14,00 \pm 1,55^{\mathrm{a}}$ & $\mathrm{MN}$ & $17,39 \pm 0,23^{\mathrm{d}}$ \\
\hline
\end{tabular}

Os níveis de acidez total, fixa e volátil são importantes parâmetros para atestar a qualidade da bebida produzida por serem responsáveis por suas propriedades organolépticas. Os resultados desses parâmetros encontram-se na Tabela 4, sendo a acidez volátil determinada pela diferença entre a acidez total e fixa.

Tabela 4 - Acidez Total e Fixa para todas as formulações

\begin{tabular}{|c|c|c|c|c|}
\hline \multirow{2}{*}{ Amostra } & \multicolumn{2}{|c|}{ Acidez Total (meq/L) } & \multicolumn{2}{c|}{ Acidez Fixa (meq/L) } \\
\cline { 2 - 5 } & Início (0 dias) & Final (42 dias) & Início (0 dias) & Final (42 dias) \\
\hline \hline B & 10,34 & 57,64 & 9,46 & 42,96 \\
\hline NB & 9,36 & 52,71 & 8,28 & 38,62 \\
\hline NI & 9,85 & 49,26 & 9,06 & 37,04 \\
\hline NA & 10,84 & 47,78 & 9,46 & 40,99 \\
\hline L & 10,34 & 54,68 & 9,46 & 39,01 \\
\hline LN & 10,34 & 49,75 & 9,46 & 39,01 \\
\hline M & 16,26 & 60,10 & 18,13 & 44,93 \\
\hline MN & 16,75 & 55,17 & 18,13 & 48,08 \\
\hline
\end{tabular}

Nota-se que os valores de acidez foram consideravelmente maiores para as formulações com maçã, devido a acidez inerente à fruta. Contudo, os valores de acidez total, fixa e volátil ficaram dentro dos limites estipulados pela legislação (Brasil, 2012). Ainda, o pH das formulações foi determinado e todas apresentaram valor final ligeiramente inferior a 4,0, valores condizentes com o encontrado na literatura (Brunelli, 2015). Nas formulações de maçã, pelo risco de produção de metanol por meio da degradação de pectina, foram realizadas análises de quantificação do composto por cromatografia gasosa. Todas as amostras com maçã apresentaram valor de metanol de aproximadamente $65 \mathrm{ppm}$, consideravelmente inferior ao limite máximo estipulado pela legislação de 350 ppm (Brasil, 2005).

\section{CONCLUSÕES}

Para todos os tratamentos realizados com a levedura Saccharomyces cerevisiae M05 da marca Mangrove's Jack, observou-se uma ótima adaptabilidade da levedura ao mosto, sendo 


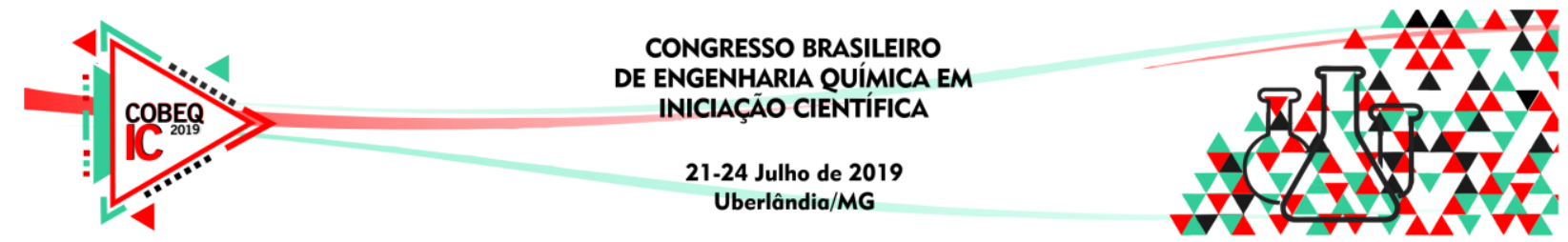

verificada pelas elevadas taxas de conversão de glicose. Quando comparadas as formulações suplementadas com as que não receberam adição de nutrientes, foi possível notar que a adição nutricional exerce pouca influência nas propriedades finais do produto. A concentração final de açúcares, produção de etanol, variação de massa, acidez e pH resultaram em valores próximos para as amostradas suplementadas ou não, mesmo com a adição dos aditivos de maçã e lúpulo. Dessa maneira, conclui-se que, para o caso da levedura estudada, a complementação nutricional pode reduzir em poucos dias o tempo de fermentação, mas não se faz necessária para a produção. Este resultado permite que o produtor artesanal poupe custos adicionais em sua produção, viabilizando o processo de fabricação da bebida que tem potencial de agregar valor aos rejeitos da extração de mel.

\section{REFERÊNCIAS}

BRUNELLI, L. T. Caracterização físico-química, energética e sensorial de hidromel. Tese (Doutorado). Universidade Estadual Paulista - Faculdade de Ciências Agronômicas, Botucatu, p. 21, 2015.

BRASIL. Ministério da Saúde e Agência Nacional de Vigilância Sanitária. Padrões Microbiológicos para alimentos. Disponível em: < http:// anvisa.gov.br>. Acesso em: 18 nov. 2005

BRASIL. Ministério da Agricultura, Pecuária e Abastecimento. Instrução Normativa ${ }^{\circ} 34$ de 29 de novembro de 2012.

BRASIL. Ministério da Agricultura, Pecuária e Abastecimento. Métodos Analíticos Oficiais para Controle de Produtos de Origem Animal e seus Ingredientes, 2017.

PIATZ, S. The complete guide to making mead: the ingredients, equipment, processes, and recipes for crafting honey wine. Minneapolis: Voyageur Press, 2014.

VIDAL, M. F. Produção de mel na área de atuação do BNB entre 2011 e 2016. Caderno Setorial ETENE, ano 3, n 30, abr. 2018.

FERNANDES, D.; LOCATELLI, G. O.; SÉRGIO, S. L. Avaliação de diferentes estirpes da levedura Saccharomyces cerevisiae na produção de hidromel, utilizando méis residuais do processo de extração. Evidência, Joaçaba v. 9 n. 1-2, p. 29-42, 2009.

MATTIETTO, R. A.; LIMA, F.C. C.; VENTURIERI, G. C.; ARAÚJO, A. A. Tecnologia para obtenção artesanal de Hidromel do tipo doce. Embrapa. Comunicado Técnico 170, p.1-5, 2006.

NAVRATIL, M.; STURDIK, E.; GEMEINER, P. Batch and continuous mead production with pectate immobilised, ethanol-tolerant yeast. Biotechnology Letters, v.12, p.977982, Jun 2001.

INTERNATIONAL ORGANISATION OF VINE AND WINE. Compendium of International Methods of Analysis of Wines and Musts. Edição 2016. Paris, França: OIV, 2016. 